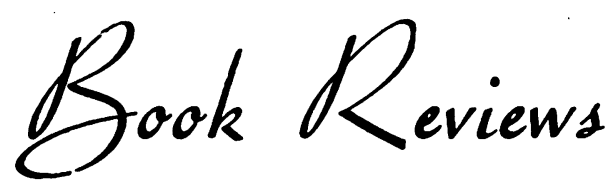

\section{THE PATHOLOGY OF TUMOURS OF THE NERVOUS SYSTEM}

By Dorothy S. Russell, Sc.D., M.A., M.D., F.R.C.P., LL.D., and L. J. RubinsteIN, M.D. First Edition. Pp. 310 + index, 286 illustrations. London: Edward Arnold Ltd. 1959. $70 s$.

Despite the mushroom growth of new laboratory techniques, histopathology is clearly no dying art. A dozen years ago the publication of a textbook devoted exclusively to tumour pathology was an event; but the last decade has seen separate monographs on tumours of bone, tumours of lymphoid tissue and so forth. Indeed, an up-to-date work on brain tumours might almost be considered overdue.

The present book is a companion to the recently published volume of 'Neuropathology' by Professor Greenfield and his colleagues. The two volumes are identical in format and lay-out, with the chapters broken up, by headings in heavy type, into readily digestible sub-sections. This makes it easy, with the aid of a well-prepared index, to find what one is looking for in a few moments. One significant difference between the two books is entirely commendable: Russell and Rubinstein wisely shun the tiresome American system of numbering the illustrations adopted by Greenfield, and stick to orthodox serial enumeration.

These illustrations are abundant-there are, for example, 26 in the chapter on meningiomas aloneand of excellent quality. This last point is of considerable importance to the general pathologist anxious to extend his experience. For this book is surely not for the specialist alone. Those who may have come to think of neuropathology as an exotic study for the highly trained few should note that the stains and techniques used on most of the preparations illustrated are within the capacity of the humblest histology laboratory.

In the chapter on the gliomata Professor Russell's wide experience lends authority to her judgment. The recent tendency, especially among clinicians, to adopt Kernohan's somewhat over-simplified grading is answered in these words : "The principle of grading, if used at all, should be restricted to autopsy material when the whole tumour can be sampled. Anaplasia is so often a localised development that no prognostic value can be attached to the grading of biopsies.'
The classification proposed retains nearly all of Bailey and Cushing's nomenclature, albeit reshuffled into four main series-glial, pineal, retinal and neuronal. 'Astroblastoma,' ' polar spongioblastoma' and ' medullo-epithelioma' are retained. 'Admittedly they are rare,' say the authors, 'but rarity cannot excuse their omission.'

Mild shocks are in store for the conventionally minded. The familiar 'pinealoma' is re-classified as an atypical teratoma. Pituitary adenomas are summarily disposed of as 'secondary neoplasms,' along with chordomas, osteomas, etc. However, none could quarrel with the chapters on meningio mas and tumours of the peripheral nerves, which are especially valuable. Professor Lumsden has contributed a chapter on the tissue-culture ob tumours of the nervous system. His work in this field is well known, and his observations are illustrated by 50 beautiful photomicrographs. The $\vec{\theta}$ conclusions which he draws from his experience ares. of of great interest and importance and cannot be adequately summarized in this review.

If one might lament an omission in what is likely to become a classic, it would be a chapter on the embryology of nervous tissue, illustrated by diagrams. The whole concept of the gliomata is so intimately related to embryonic cell-types thac some knowledge of their origin and development is essential to a clear understanding of brain tumours. Perhaps in the second edition ....?

\section{PSYCHOPHARMACOLOGY FRONTIERS}

Edited by N. S. KLINE, M.D. Pp. 533. London: J. \& A. Churchill Ltd. 1959. $72 \mathrm{~s}$.

Co-ordinating and editing the scripts of the symposium on psychotropic drugs, held during the second International Congress on Psychiatry in 1957, undoubtedly ranks with the Twelve Labours, and Dr. Kline has completed his Herculean task with evident success. Over 90 members participated, and five languages were used, and without the generous support of leading drug houses this volume would not have been available in its present form. The editor has managed to contain within one pair of covers 65 separate papers, in addition to appendices, and an interesting feature is the in- 